\title{
EL PADRE ISLA Y SU FAMILIA EN SANTIAGO
}

\author{
por \\ JOSÉ MARTÍNEZ DE LA ESCALERA
}

Sobre la primera estancia del joven Isla en Galicia, durante el segundo y tercer decenio del ' 700 , no recogieron los primeros biógrafos informaciones concretas, y hasta hoy se han mantenido datos y fechas equivocadas, que conviene precisar.

El fiel compañero de sus últimoṡ meses de vida, el berciano D. Antonino de Soto Valcarce ${ }^{1}$, escribe en una semblanza necrológica de 1783: "nada puedo decir en particular de su primera educación en el siglo"2. Salas/ Tolráa ${ }^{3}$ aún contando con el asesoramiento y quizá revisión de María Francisca de Isla, no menciona como lugares de residencia en veintiún años sino tres: Valderas, Villagarcía y Salamanca. A pesar de la importante documentación inédita que han aportado Miguel Bravo Guarida ${ }^{4}$ y Albano García $\mathrm{Abad}^{5}$, nada dicen de esta primera etapa compostelana. Los colaboradores de El Padre Isla. Su vida, su obra, su tiempo ${ }^{6}$ mantienen todavía algunos datos inaceptables.

\footnotetext{
${ }^{1} B A E, \mathrm{XV}, 552 \mathrm{~b}$.

${ }^{2}$ Carta a Christian Gottlieb von Murr, editor en Nurenberg del Journal zur Kunstgeschichte und zur allgemeinen Literatur, XI, 236.

${ }^{3}$ Josef Ignacio de Salas (=Juan José Tolrá), Compendio de la Vida, caracter moral y literario del célebre P. Isla... Madrid, 1803.

${ }^{4}$ Genealogía del P. Isla: Archivos Leoneses 5 (1949) 6-37.

${ }^{5}$ Correcciones y nuevos datos sobre la biografia del P. Isla: Revista de Literatura 35 (1969) 39-55.

${ }^{6}$ León, Diputación Provincial, 1983.

"CUADERNOS DE ESTUDIOS GALLEGOS", Tomo XLI, Fascículo 106, Santiago 1993-94.
} 
Narciso Alonso Cortés publicó la información abierta en Santiago en $1726^{7}$ sobre la nobleza de D. José Isla de la Torre (así firmará siempre), que fue ejecutada favorablemente por la Chancillería de Valladolid en 1729. En ella constan los sucesivos empleos del hidalgo de Colunga como teniente del alférez mayor en su municipio natal, corregidor luego y gobernador de Valderas, alcaide de la fortaleza y juez de Astorga y por fin, alcalde mayor y superintendente general del condado y estados de Altamira y administrador en el Reino de Galicia y Principado de Asturias de los bienes y rentas a ellos pertenecientes.

Podía suponerse a priori que tan universal superintendencia administrativa habría generado abundante documentación notarial; y efectivamente la ofrece el Archivo Histórico Universitario de Santiago (=AHUS), y con ella datos desconocidos sobre los padres y el hijo.

Pieza capital y resumen de la vida del hidalgo asturiano es su testamento, otorgado el 22 de febrero de $1756^{9}$. Antes de tomar las disposiciones y hacer las mandas acostumbradas, resume su vida familiar y social. Hijo de Domingo de la Isla Cobián, regidor por el estado noble del concejo de Colunga, y de Catalina Pis de la Torre, también noble, vecinos de Loroñe o Loroni, parroquia de Santiago de Gobiendes, salió de su patria para servir a los condes de Altamira ${ }^{10}$. Se casó en Madrid, "en la casa y oratorio de sus excelencias", con Dña. Ambrosia Rojo y Cordido (que le aventajaba en 17 años), el 4 de junio de $1701^{11}$, ante Fr. Angel de Soto

\footnotetext{
${ }^{7}$ Los protocolos de Juan Sánchez de Andrade no se conservan. Datos genealógicos del P. Isla: BRAE 23 (1936) 211-224, reproducido en Sumandos biográficos, Valladolid, 1939, 71-90.

${ }^{8}$ En 1724 los estados de Altamira se componían de 15 partidos, jurisdicciones o merindades; 14 en Galicia (cf. Compostellanum, 37, 1992, 515).

${ }^{9}$ AHUS, Juan García Vaamonde, prot. 5162, f. 40-43.

${ }^{10}$ En el padrón de Colunga de 1700 se le da por ausente como "corregidor en Castilla"; lo mismo en el de 1704. En 1703 fue nombrado Gobernador de la jurisdicción de Rivesla, de las posesiones de Altamira, con residencia en Vidanes; lo que explica el bautismo, y sin duda el nacimiento, allí de su hijo (A. García Abad, a.c., 44s).

11 "En la villa de Madrid, a quatro de Junio de mil setecientos y uno, yo fr. Angel de Soto,... en virtud de un mandamiento del Sr. Licenciado D. Alonso Portillo y Cardos, vicario de Madrid y su partido, que pasó ante Juan Phelipe de Lara, notario, su fecha de treinta y uno de Mayo de dicho año,... desposé solemnemente a D. Joseph Isla de la Torre con Dña. Ambrosia Roxo, siendo presentes testigos D. Pedro de Castro y D. Joseph Alvarez y D. Lucas Román, y padrinos los Sres. D. Antonio Moscoso, conde de Altamira, y Dña. Theresa Moscoso, su hermana. Hice este desposorio en la calle de las Rejas, en casas de
} 
OSB, teniente cura de la parroquia de San Martín. Nada dice de sus actividades en los años inmediatamente sucesivos, pero por otros documentos lo encontramos actuando en Santiago en 1715 como "gobernador de Valderas y juez de residencia en las jurisdicciones de la casa de Altamira", según poder otorgado por el conde en Madrid ${ }^{12}$. No consta si para entonces se había trasladado ya la familia a Compostela, pero ya residía en 1716, año en el que el conde D. Antonio de Osorio y Moscoso Phelipez de Guzmán le dio poder general para administrar sus estados ${ }^{13}$. En el Vecindario general de 1717 (se han perdido todos los posteriores del siglo) aparece "D. José de Isla, asturiano" domiciliado en la parroquia de San Benito ${ }^{14}$. Quizá no se había instalado aún definitivamente, pero lo hará muy pronto en el cercano palacio de Altamira, en donde residirá hasta su muerte ${ }^{15}$.

dicho Sr. conde de Altamira. Y lo firmé." (Arch. S. Martín, L. 12, f. 214). En el acta notarial del 24 de mayo declara el Sr. Isla que lleva tres años viviendo en Madrid, en casas de la condesa de Altamira, a la Encarnación. Dña. Ambrosia Roxo Hurtado, hija de D. Tomás Roxo y Dña. Jacinta Montenegro, lleva dos años y medio viviendo en las casas de la condesa de Altamira, a la Encarnación; antes residió en Almazán dos años y medio; antes en Cerdeña seis años continuos; antes en Valencia dos años y medio y antes en Madrid dos meses: y todo este tiempo ha estado en compañía y el servicio de la condesa. Del marido se dice que era "asistente en Almazán en casa de Altamira". Dña. Ambrosia firma "Roxo Hurtado y Montenegro". No aparece para nada el apellido Cordido. 15.

${ }^{12}$ El 15.4.1715 ante Manuel de Matute: lo reproduce Simón Rodríguez, 3647, f. 7 y

${ }^{13}$ El 30.9.1716, ante Manuel de Matute (prot. 14673, f. 252ss) y lo reproduce Simón Rodríguez en diversos contratos (3647, f. 324, 3652, 3654). El conde había obtenido Cédula Real del 18.3.1714 por la que se le reconocía pleno derecho a sus 23 años para administrar sus estados (Simón Rodríguez, 3647, f. 1). Sobre la familia Moscoso: C. Martínez Barbeito, Torres, pazos y linajes en la provincia de La Coruña. La Coruña, Everest, 1986, 391.

${ }^{14}$ En una casa de la plaza de San Benito vivía y fallecerá en 1774 su yerno Nicolás de Ayala (testamento ante José A. de Neira, 1771, 5286, f. 8).

${ }^{15}$ El palacio de los condes de Altamira, rodeado de amplia huerta, estaba situado entre la iglesia parroquial de San Félix de Solovio y la conventual de San Agustín, de la que eran patronos los condes y en la que tenían "bóveda" sepulcral para ellos y sus servidores. Nada se conserva hoy de la posesión, adquirida en 1870 por el Ayuntamiento para plaza pública de abastos (expediente en el Archivo Municipal). Vease A. Cotarelo Valledor, El palacio de Altamira en Compostela: Anales Universidad de Madrid, III-3 (1934); tirada aparte de 7 p. Reproduce croquis de la fachada y plano del conjunto. En él tenían su residencia los alcaldes mayores, como se afirma expresamente en un contrato de 1718 con el maestro de arquitectura Domingo López sobre ciertas obras en el interior del palacio (Simón Rodríguez, 3651, f. 49).

"CUADERNOS DE ESTUDIOS GALLEGOS", Tomo XLI, Fascículo 106, Santiago 1993-94. 
Ahora comienza por consiguiente la vida compostelana de José Francisco Isla (no usa todavía el de), y su frecuentación del vecino colegio de la Compañía ${ }^{16}$. El P.C. Eguía afirma que ya había sido alumno en el de Monforte de Lemos; es probable, dada la cercanía de la residencia astorgana de la familia, pero no se conocen pruebas que lo confirmen. Su primer maestro de gramática había sido un joven de Valderas, Manuel Pérez; y al ingresar éste en la orden dominicana, pasó al colegio de los carmelitas calzados en la misma villa. El trato con los religiosos despertó una afición, que creció hasta el propósito de comenzar el postulantado para el ingreso en la Orden.

En el colegio de Santiago siguió evidentemente los cursos de humanidades clásicas, que le suministrarán la base de su cultura literaria. No sabemos con qué fundamento afirma Salas/Tolrá que estudió "la filosofía cuando otros comienzan a escribir planas, y la filosofía le abrió las puertas a otras ciencias mayores con tanta anticipación que a los once años de su edad se graduó de bachiller en leyes, haciendo al mismo tiempo iguales progresos en el Derecho Canónico, en la Historia y en la Poesía". La hipérbole, cuando no fantasía, no puede ser más evidente. Los once años (1714) los había cumplido, si no en Valderas, en Monforte o Astorga, donde no cabía la posibilidad de seguir estudios mayores. Pudo comenzar en Santiago la filosofía; pero de todos modos esto no le eximirá de tener que seguir los cursos regulares entre 1721 y 1724. De unos estudios y graduación in utroque iure no hay el menor rastro en todos sus escritos. Para apreciar la exactitud de las afirmaciones que hace Salas/Tolrá conviene recordar que según él "apenas cumplía los diecinueve (1722)... dio a luz la traducción de la Historia del grande emperador Teodosio...". Consta ahora por su correspondencia de Salamanca ${ }^{17}$, que comenzó la traducción al llegar a ella (1724) y no quiso publicarla hasta terminar los años de formación, en 1731.

Sobre la evolución espiritual del estudiante comunica Salas/Tolrá dos informaciones no comprobables, y sólo la segunda plenamente lógica. La primera es la de un proyecto matrimonial ( $i$ a qué edad, cuando en Valderas había brotado una posible vocación carmelitana? A no ser que se tratase

\footnotetext{
${ }^{16}$ Lo describe en detalle E. Rivera Vázquez, Galicia y los jesuitas. La Coruña, 1989, 224 s y 590 s.

${ }^{17}$ Ver mi art. Primeros escritos del P. Isla...: Miscelánea Comillas 39 (1981) 149-181.

"CUADERnOS DE ESTUdiOS GALLEGOS", Tomo XLI, Fascículo 106, Santiago 1993-94.
} 
de un proyecto familiar a larga distancia, enriquecido luego por la imaginación de María Francisca). La segunda, unos ejercicios espirituales en un colegio de jesuitas, sin duda el de Santiago, de los que salió con la firme decisión de solicitar su admisión en la Compañía. De esto último sí encontramos ahora una prueba insospechada y poco frecuente. E1 28 de abril de 1719 se presentó el adolescente de 16 años recién cumplidos acompañado de sus padres, ante el escribano Simón Rodríguez ${ }^{18}$, y después de recabar y recibir la bendición y consentimiento de estos, de lo que el notario da fe, declaró que "desde algunos días a esta parte tiene por su propia voluntad fixa determinación de entrarse en la sagrada religión de la Compañía de Jesús, a que se halla admitido y muy próximo a recibir la ropa con licencia del Rmo. P. Provincial..."; por lo cual "atendiendo a que en dicha sagrada religión tiene y se le ha de dar lo bastante para:su sustento, adorno y remedio de sus necesidades, de su libre y espontánea voluntad, sin fuerza ni persuasión de dichos sus padres... cede, renuncia y hace gracia y donación pura, mera, perfecta e irrevocable... de todos y cualesquiera bienes temporales o transitorios... que pueda y deba heredar... en favor de dichos sus padres... para que ellos dispongan a su eleción y arbitrio...". Sigue la prosa jurídica especificando la universalidad, estabilidad y perennidad de la renuncia, contra la cual "no irá ni reclamará en tiempo alguno alegando el que no pudo hacerla donar ni renunciar lo que necesitaba para sí, ni por otra causa pensada o no pensada... y si lo intentase hacer y contravenir... quiere y consiente no se le siga ni admita acerca de ello en juicio ni fuera del, y que se le condene en las costas que se ocasionaren, porque quiere valga por su última y determinada voluntad... y la misma obligación hace de que no la revocará ni variará en manera alguna. Y por hallarse debaxo de la patria potestad y su menor edad, también renunció las que según ella pueda o deba renunciar...". Todo ello lo ratifica con expreso juramento, del que protesta "no pedirá absolución ni relajación al Papa ni a otra autoridad, ni usará de la que motu proprio se le pueda conceder", "y otras cuantas veces lo hiciere, otros tantos juramentos hace y uno más prometió de así lo cumplir, pena de perjuro y de caer en caso de menos valer".

Es sabido que la renuncia de los bienes presentes o futuros ha sido considerada en todas las órdenes religiosas como el paso previo indispen-

${ }^{18}$ AHUS, S. Rodríguez, 3664 (1719) f. 120 s.

"CUADERNOS DE ESTUDIOS GALLEGOS", Tomo XLI, Fascículo 106, Santiago 1993-94. 
sable para la incorporación jurídica del aspirante. Para salvaguardar la libertad y espontaneidad de tal acto, dispuso el concilio de Trento que sólo sería válido si se efectuaba poco antes de la profesión, con la que se ponía fin al único año de noviciado. Los jesuitas fueron expresamente autorizados por el concilio para seguir con la norma impuesta por las entonces recientes Constituciones ignacianas, es decir, la condición de disponibilidad en el novicio para hacer la renuncia si el Padre General lo pedía, una vez cumplido el primer año de noviciado. Todos los canonistas ${ }^{19}$, al tratar este punto, advierten que las renuncias hechas antes del ingreso, incluso las motivadas por el propósito de realizarlo, no están sujetas a ninguna autorización previa ni afectadas de posible invalidez. En los protocolos de Simón Rodríguez de esos años aparecen numerosas renuncias de novicios y novicias de los conventos compostelanos y también de jesuitas jóvenes: pero éstos eran ya religiosos con votos, y aquellos estaban en disposición próxima de serlo, por lo que presentan la licencia del superior mayor respectivo, que queda incorporada al protocolo. Lo singular de la determinación del joven Isla no es el texto, que con sus repetidos juramentos para cerrar el camino a toda posible retractación, no difiere del de otras renuncias registradas por el mismo escribano, sino que se anticipa al noviciado, tiempo esencialmente de prueba, tanto para el aspirante como para la Orden. Es una decisión que en su precocidad entronca en línea directa con el espíritu de los Ejercicios ignacianos y su consideración llamada "de los tres binarios de hombres"; no parece probable que se hayan dado muchos ejemplos.

Ignoramos la reacción de D. José Isla ante la vocación de su hijo único, de cuya madura y prometedora precocidad sin duda se sentiría orgulloso. Encontraríamos quizás aquí la raiz de la sorda tensión entre ambos, que sorprenderemos en diversos momentos de su vida, y de la que el testamento de 1756 sería una prueba evidente, si diéramos crédito a lo que comenta el P. Isla en 1761 al matrimonio Gortázar-Montiano, de Bilbao, con el que mantenía una íntima correspondencia ${ }^{20}$ : "Habiendome dado Dios por padre a uno de los hombres más capaces que he conocido, otorgó su testamento, que en lo sustancial consultó conmigo; y haciendo en él memoria

${ }^{19}$ A. Barbosa, Collectanea Doctorum (1686) 647; L. Ferraria, Bibliotheca canonica (1760) V, 1373.

${ }^{20}$ Miscelánea Comillas n. 43 (1965) 469 y 468.

"CUADERNOS DE ESTUdios GALLEGOS", Tomo XLI, Fascículo 106, Santiago 1993-94. 
de todos los demás hijos (somos siete entre todos), por él no consta que yo lo sea suyo. Hiceselo observar, y por poco no me regala con una manta de palos, de la corona y de las canas abajo. Reíme y dejélo así, considerando que este es el remedio mejor contra casi todos los disgustos. Por este ligero échantillon podrá inferir vmd con quien lidio..". Y unos meses antes decía al mismo corresponsal: "lidio con un viejo, en cuya comparación fue un terrón de azucar el héroe del Misántropo; sacrificado a su clava, más pesada que la de Hércules, para libertar de ella a media docena de víctimas".

Tal silencio en el más importante documento público de una vida sería de veras inaudito; pero hoy podemos comprobar que la realidad fué muy diferente. Después de mencionar su primer matrimonio, D. José Isla continúa: "y constante matrimonio tuvimos por hijo único legítimo al Padre José Francisco Isla, religioso profeso que es en la sagrada religión de la Compañía de Jesús, el cual estando para entrar en dicha religión, hizo renuncia en mí y en su madre de todos los bienes que le podían pertenecer de sus legítimas o por cualquier otro título, de que dio fe Simón Rodríguez, escribano de número y del cabildo compostelano, el día...". En consecuencia, declara por únicos herederos a tres de los seis hijos del segundo matrimonio, José Joaquín y las solteras María Isabel y Antonina Cándida. En el testamento de Dña. Rosa María Losada, otorgado en 1757, figuran ya estos tres como herederos universales, y a José Joaquín se le declara "primer sucesor en el vínculo"21. A María Francisca, que "llevó al matrimonio todo el dote que pudimos darla", le concede como madre su bendición y cariño. Nada dice de los otros hijos, el benedictino Joaquín José y el jesuita Ramón José22. En sus cartas a Gortázar el P. Isla se refiere a la muerte de su madrastra, "a quien amaba y de quien era amado como si fuera madre"; esto se deduce ya de sus afectuosas cartas de estudiante.

${ }^{21}$ El testamento en AHUS, Juan García Vaamonde, 5163, f. 17s. El vínculo del mayorazgo se estableció por escribura del 6.6.1750 y otra posterior del 23.21.1754 ante el escribano Pedro de Villasalgueiro o Villasalgado, cuyos protocolos no se conservan. La dote de María Francisca, según el testamento de su marido (prot. de José A. de Neira, 5286, f. 8) fue de 40.000 reales, 30.000 en efectivo y el resto en alhajas, que se especifican.

${ }^{22}$ La repetición del antropónimo José en la familia Isla confirma lo que sabemos de otros lugares castellanos contemporáneos. En 8 parroquias de Valladolid se cuenta el $0,8 \%$ de Josés para 1596-1600; el 5,8\% para 1646-1650 y el 12,2\% para 1696-1700 (José de Jesús García OCD, "San José en la antroponimia en Valladolid", en: Présence de SaintJoseph au XVII siècle = Cahiers de Joséphlogie 35, 1987, 511-520).

"CUADERNOS DE ESTUDIOS GALLEGOS", Tomo XLI, Fascículo 106, Santiago 1993-94. 
Del mayorazgo José Joaquín, que en ese momento (1762) se encontraba en Madrid, dice ${ }^{23}$ que "soñó montones de oro donde no había más que montones de basura, y piensa atropellar a sus hermanas, que no tienen otro escudo ni otro padre que a mí... Desde que comenzó a hablar hasta ahora... no ha sabido más que darnos pesadumbres, y con ellas aceleró la muerte de sus padres".

Poco después de la partida del joven Isla para el noviciado, vivió Galicia y por consiguiente Santiago semanas de angustia. Una escuadra inglesa llevó a cabo una expedición de castigo en las costas gallegas, como respuesta a la guerra declarada por el ministro Alberoni con la conquista de Cerdeña y Sicilia y la protección de Jacobo Estuardo, pretendiente al trono inglés, lo que provocó la formación de la Cuádruple Alianza ${ }^{24}$. El almirante Michells atacó el 27 de septiembre el puerto de Rivadeo, y sólo se retiró cuando hubo cobrado 2.400 pesos y un tributo en animales y vitua1las. Después de hostigar diversos puertos de la costa coruñesa, desembarcaba el 10 de octubre en las playas de Vigo; el 19 se rendía la fortaleza del Castro al general lord Cobham, y quedaban los ingleses dueños de la ciudad. Se internaron luego por la ría, y penetrando por la desembocadura del Ulló, no fortificada, sorprendieron el 25 a la indefensa Pontevedra, que en el transcurso de una semana fue saqueada e incendiado el palacio arzobispal y la maestranza. El marqués de Risbourq, virrey y capitan general de Galicia, participó a las siete ciudades del Reino su temor de un inminente ataque a la provincia de Santiago, por lo que ordenaba una leva general de vecinos, mientras no llegaban las tropas regulares prometidas de Castilla. En Santiago se presentaron 150 voluntarios. El Cabildo hizo transportar las reliquias de la Catedral al monasterio de Sobrado, y los papeles del archivo, alhajas y caudales a Lugo. Los temores se convirtieron en certeza al recibirse en la Curia arzobispal el ultimatum de lord Cobham, fechado en Vigo el 26 de octubre, por el que exigía a la Mitra y a la Ciudad un tributo de 60.000 doblones y otros 5.000 por la ciudad de Pontevedra ${ }^{25}$.

El hostigamiento de las milicias populares viguesas, el temor a las anunciadas tropas de Castilla y las insubordinaciones y deserciones entre los

${ }^{23}$ A.C., 482 y 487. José Joaquín, a los siete años (el 5 de mayo de 1739) había recibido la primera tonsura en ceremonia especial tenida en la capilla del palacio arzobispal de Santiago.

${ }^{24}$ A. Meijide Pardo, La invasión inglesa de Galicia en 1719. Santiago, Instituo P. Sarmiento, 1970. El autor se limita estrictamente a los episodios bélicos.

${ }^{25}$ A. López Ferreiro, Historia de la S.A.M. iglesia de Santiago, X, 16.

"CUADERNOS DE ESTUdiOS GALLEGOS", Tomo XLI, Fascículo 106, Santiago 1993-94. 
invasores, aconsejaron el repliegue y reembarque en los primeros días de noviembre. Pronto los vigías de los fachos anunciaron el paso de la flota hacia el Norte.

Quedaban las secuelas del conflicto. En junio de 1720 se concedió por un Real Despacho el repartimiento en la provincia de Santiago de los gastos ocasionados por la defensa y sostenimiento de los voluntarios, y para devolver las cantidades adelantadas por particulares del comercio. Importaba todo 54.640 reales $^{26}$. De todos los alcaldes y jueces afectados sólo D. José Isla protestó. (A la jurisdicción de Altamira le cargaban en conjunto 13.562 reales). En su representación al fiscal del Consejo alega que "gastó esta ciudad 44.323 reales en crecidas ayudas de costa a sus regidores, en un socorro a sus ministros ordinarios, en el preé (sic) de 300 o 400 hombres que de allí salieron a distancia de tres leguas..., en una novena de Ntra. Sra. de la Cerca y en otros gastos muy opuestos al beneficio de la Causa pública". Y siendo gastos de la Ciudad, no se podían cargar a la Provincia, que había contribuido con 6.000 hombres ni a los vasallos de Altamira. Isla negaba además que la ciudad de Santiago tuviese "jurisdicción por derecho y leyes reales para mandar en dicho estado de Altamira y menos para tratar a sus Jueces con imperio y sin la urbanidad que se practica entre Justicias de igual jurisdicción, y por consiguiente le falta poder para despachar ministros, siendo preciso que para uno y otro le tenga particular de su Magestad y o de algún señor superior...".

El Consejo, oidas todas las partes y con el informe del Capitán General, aprobó en agosto de 1721 lo propuesto por la Ciudad. El informe fiscal propone al Rey que desestime las quejas de Isla, y desapruebe sus procedimientos y el modo de tratar a la Ciudad. En la comunicación oficial a ésta se le previene a Isla cuán del Real desagrado ha sido su osado proceder, y el debido respeto con que a lo adelante debe tratar a VS y obedecer sus órdenes, que es cuanto pudo conseguir mi instancia separando al señor Conde su amo por no contemplarle parte en semejante arrojo, ni comprender a los demás señores que tienen estados en este Reino, en una segura indignación y resolución que tomara su Magestad, enterado de las malas consecuencias que podían seguirse a su Real servicio usando sus Alcaldes mayores del imperio que pretendía tener dicho Isla en las Jurisdicciones de su amo, de que juzgo se abstendrá, y para ello conviene

${ }^{26}$ El expediente se conserva en AHN, Consejos, leg. 4190/6; las copias de resoluciones y decretos, en los libros de Consistorios compostelanos.

"CUADERNOS DE ESTUDIOS GALLEGOS", Tomo XLI, Fascículo 106, Santiago 1993-94. 
mande VS hacer notorio el Despacho dejandole copia...

Efectivamente el 11 de octubre se hizo la notificación en el palacio de Altamira.

Por esos meses José Francisco estudiaba filosofía en el vecino colegio de la Asunción, a donde había llegado desde Villagarcía ese verano. Ignoramos sus reacciones ante estos hechos. El alcalde mayor, tan públicamente desautorizado, siguió por de pronto en el desempeño de sus funciones ordinarias. En los protocolos de Simón Rodríguez de esos años se encuentran numerosas escrituras de aforamiento y otros contratos otorgados por Isla. Se adivina la mano firme de un administrador que pone orden en la hacienda de su amo, descuidada quizá durante la minoría de edad de éste.

El estudiante entre tanto se entregó dócilmente a los estudios que se le imponían, aunque sin duda múy pronto llegó a la conclusión que "esta carrera no es de mi genio", como escribirá más tarde desde Salamanca a su corresponsal, el franciscano santiagués fr. Antonio Barros ${ }^{27}$.

"Su genio" se manifestó en pequeños escritos de circunstancias, que conservó entre sus papeles, como primeros hijos, hasta el expolio de 1767. Una salutación en latín al nuevo arzobispo de Santiago (1723), Herrero y Esgueva; composiciones poéticas en el cumpleaños del profesor de filosofía; un vexamen a varios colegiales de Fonseca; traducciones de los italianos Tesauro y Bartoli; un elogio de Felipe V con motivo de su renuncia al trono; una meditación en ausencia de su mejor amigo, Isidro Romero de Leis, colegial de San Clemente de Santiago. Estos y otros escritos están firmados por "Francisco José de Montenegro", que no puede ser otro que Isla $^{28}$. De estos años compostelanos es la consolidación de firmes amistades de condiscípulos o relaciones de familia, con los que mantendrá correspondencia en los años siguientes, en la que se revelan interesantes facetas de su personalidad.

${ }^{27}$ Fr. Antonio Barros (Padrón, 169? - Nápoles, 1755), lector de teología en Toro y Oviedo por estos años; luego guardián del convento de Santiago y constructor de la iglesia, Ministro provincial y Procurador de la Orden, editor de las obras de Duns Scoto (Arch Ibero-Am, 1928-2, 1971, 333-343, 355-359).

${ }^{28}$ Además de ser un apellido materno, en sus cartas de este año juega con el sentido antifrástico de "dar en el blanco" a propósito de sus sátiras anónimas y no descubiertas; y en las cartas a Gerónimo Puig de 1740 se firma "Antonius Mons Niger", con el mismo sentido.

"CUADERNOS DE ESTUDIOS GALLEGOS", Tomo XLI, Fascículo 106, Santiago 1993-94. 
El último curso en Santiago se vió ensombrecido por la enfermedad y muerte de su madre. En junio de 1722, "dentro del palacio de Altamira, y... con achaques habituales de muchos días", había dado Dña. Ambrosia poder para testar a su marido, con el que se sentía plenamente identificada, $y$ al que nombra cumplidor, albacea y heredero universal. En septiembre del año siguiente otorga otro poder, por el que modifica el lugar de su enterramiento: no en el que tenían los condes en la iglesia de San Agustín, sino en la iglesia del colegio de la Compañía (sin duda porque entretanto había obtenido la preceptiva licencia del P. General, como lo hará su marido treinta años más tarde). Dña. Ambrosia falleció el 3 de marzo de 1724, y el 12 formalizaba su viudo las últimas voluntades de la difunta, lo que nos permite conocer curiosos detalles en los que se combinan la mentalidad burguesa y el espíritu cristiano ${ }^{29}$.

Amortajado con el hábito franciscano, fue conducido el cadáver por cuatro pobres y asistido de 18 sacerdotes, pero "sin pompa ni circunstancias que la acreditasen,... gustando de que su entierro fuese sin la ostentación que se estila en esta ciudad en los de las demás personas nobles y autorizadas". Por la misma razón no habría "ofrenda", y las "cinco comunidades mendicantes de la ciudad"30 celebrarían cada una en su convento la vigilia, misa y responso en los tres días de entierro, honras y cabo de año, sin concurrir al entierro, para escusar la indecencia y poca devoción que se experimenta concurriendo todas a una iglesia; y se les diese la misma limosna que se daba sin esta circunstancia, con tal que tocasen las campanas para despertar la devoción...". A los cuatro pobres se les dió "un vestido entero de paño de la sierra".

Precisiones semejantes se repetirán en el testamento de D. José Isla en

\footnotetext{
${ }^{29}$ AHUS, Simón Rodríguez, 3655 (1722) f. 15; 3660, f. 43.

${ }^{30}$ Domingo González Lopo (Actitud ante la muerte en la ciudad de Santiago durante los siglos XVII y XVIII: la actuación de las órdenes mendicantes: Liceo Franciscano 38 (1985) 147-165) cuantifica en el 87,39\% la elección de la mortaja franciscana en la ciudad para los años 1700-20, y confirma la presencia de las "cinco comunidades" (dos de franciscanos, agustinos, dominicos y mercedarios) a principios del 700 para personas de posición elevada. Señala también la evolución -sin precisar fechas- hacia la celebración de los oficios en la iglesia propia de cada una de ellas, por los mismos motivos. Parecidos datos en: La mortaja religiosa en Santiago entre los siglos XVI y XIX: Compostellanum 34 (1989) 271-295. En Oviedo se cuenta el 78\% de los hombres y el 65\% de las mujeres (Roberto J. López, Oviedo: muerte y religiosidad en el siglo XVIII. Oviedo, 1985).
} 
1756. Los sacerdotes acompañantes serán 24 , y las cuatro comunidades ${ }^{31}$ mendicantes celebrarán las exequias en sus respectivas iglesias "para excusar la confusión e indevoción que causan muchas misas cantadas a un tiempo en una iglesia". No se llamará a la cofradía de la Concepción ni se tocarán las campanas de la catedral; y lo destinado a esto más 200 reales se darán a seis pobres, pero no a la puerta de la casa mortuoria, "como se estila, porque me parece que de esta costumbre resultan más inconvenientes que beneficios". "No se permitirá que al lado de mi cadáver asistan como es costumbre aquellas cuatro personas que de distinción comunmente acompañan a la caja, porque esta ceremonia nada es conducente para el alivio de los difuntos, y sólo sí cuatro palanquines ${ }^{32}$ pobres llevarán la caja, y se les dará de limosna por este trabajo a quince reales cada uno".

Con el curso 1723-24 concluyen para José Francisco los estudios de la filosofía. El 28 de diciembre anterior había recibido, juntamente con sus condiscípulos, como era costumbre, las órdenes menores en la capilla del palacio arzobispa ${ }^{33}$.

En septiembre se trasladan a los dos colegios dedicados a los estudios teológicos: el del Espíritu Santo en Salamanca y el de San Ambrosio en Valladolid. La distribución la.hacía alternativamente el P. Provincial, atendiendo al orden de los méritos académicos. A Isla le tocó Salamanca.

Nada sabemos de su acomodación a un ambiente universitario más rico y variado que el compostelano, y en un colegio que ha conservado hasta hoy la sobria esplendidez del barroco. Pronto un suceso inesperado le va a proporcionar la ocasión de su primera salida literaria.

El 3 de enero de 1725 fallecía en Madrid D. Antonio Gaspar de Moscoso y Benavides, conde de Altamira y marqués consorte de Astorga; y el 28 de febrero le seguía a la tumba su hermanastro, D. José de Moscoso y Aragón, duque consorte de Nájera. El luto afectaba muy directamente a la familia Isla. El estudiante de Salamanca se asoció a él con un escrito, publicado sin duda a expensas de su padre, titulado: Carta de un residente en la Corte de Madrid para otro residente en la Corte de Roma, sobre el asumpto

\footnotetext{
${ }^{31}$ Los mercedarios de Conxo, que regentaban la parroquia, excusaron con frecuencia esta asistencia.

32 "... los que en Santiago se llaman palanquines, y en otras partes hermanos del trabajo", escribe el P. Isla a su amigo Cernadas en 1758 (Obras del cura de Fruime, III, 16).

${ }^{33}$ Arch Hist. Dioc., Libro de Órdenes, 1053, f. 125 v.
} 
de las Vidas, con ocasión de las inmediatas muertes de los Excmos. Hermanos, el Excmo. Señor Marqués de Astorga, Conde de Altamira; y el Excmo. Señor Duque de Nájera ${ }^{34}$. Son en realidad dos cartas, fechadas el 3 de enero y el 28 de febrero, firmada la primera con las iniciales de J.F.I., y la segunda con el rebuscado anagrama "Joachin Federico Issalps". Quizá como recuerdo afectuoso a ésta su primera "persona" literaria, utilizó el mismo para su última producción, la traducción del Gil Blas de Santillana, y por un momento pensó firmar así el Fray Gerundio.

Después de unas consideraciones sobre la labilidad de la vida humana, para lo que se sirve de una descripción del río Mosa hecha por el jesuita italiano Daniello Bartoli (uno de sus modelos literarios), recuerda Isla lo que había presenciado durante la visita a Santiago realizada por el conde en el verano de 1721, y describe con juvenil lozanía el entusiasta recibimiento dispensado por la ciudad. Pondera las esperanzas que se habían suscitado con el nuevo reinado y el papel que en él parecía tener reservado el joven conde, y medita sobre la precipitada decadencia corporal de los últimos meses y las "portentosas disposiciones" decididas por el conde para su entierro: en el camposanto de los pobres de la Buenadicha, con la mortaja de San Francisco, sin funerales solemnes, y llevando "en memo-

\footnotetext{
${ }^{34}$ Uriarte, Anónimos y seudónimos..., 296. Unico ejemplar conocido, en Biblioteca de Palacio, III-6537, f. 123-139. El conde de Altamira había nacido en Valencia en 1689, durante el virreinato de su padre. Se casó en 1717 (no murió soltero, como afirma SaintSimon y le sigue Alfonso Danvila) con Dña. Ana Osorio de Guzmán, marquesa de Astorga. Pronto comenzó a brillar en la Corte, introducido por su madrastra, Dña. Angela Folch de Cardona y Aragón, camarera mayor de Isabel Farnesio, como sucesora de la princesa de los Ursinos, y luego de la joven Reina. Como sumiller de corps del Príncipe, fue uno de los pocos señores en los que Luis depositó su confianza, y se le auguraba la mejor situación en el futuro reinado. Efectivamente, hizo funciones de alférez mayor en la proclamación de Luis I, no se apartó de su lecho de muerte y condujo el ataud al Escorial. El duque de SaintSimon traza este retrato al buril: "Il était bien fait, appliqué, peu répandu, de l'esprit, de la conduite, fort grave, fort dévot, fort mesuré, fort espagnol... l'air d'un gran seigneur, mais un air un peu embarrassé et très réservé, et une politesse qui semblait vouloir bien faire à travers la crainte d'en trop faire... Il avait déjà rétabli toutes les étiquettes espagnoles et aboli tout ce qui n'était pas des manières et des coutumes antiques. On pouvait dire de lui que c'était un jeune seigneur qui n'avait point vieilli depuis le temps de Philippe II... On commençait déjà de mon temps à le compter beaucoup; il savait et s'appliquait fort à la lecture, et je ne sais qui aurait pu l'apprivoiser" (Mémoires, ed. 1883, XII, c. VII, p. 1160). Más datos en Alfonso Danvila, El reinado relámpago. Madrid, 1952. El punto de vista francés en: A. Baudrillart, Mission du Maréchal de Tessé, 1724: Revue des Questions Historiques 60 (1896) 485-561.
}

"CUADERNOS DE ESTUDIOS GALLEGOS", Tomo XLI, Fascículo 106, Santiago 1993-94. 
ria del Cordón de Sancti Spiritus, que estaba esperando remitido por el Rey Cristianísimo, una áspera soga al cuello".

El escritor, vibrante de emoción contenida, elogia sus talentos de gobierno y encuentra modo de insertar un retrato del hidalgo asturiano, que administraba los estados de la casa condal.

Atendió principalmente, con escrupulosísimo cuidado, a la elección de las personas que substituía para el gobierno de sus estados; pero con mucha mayor especialidad a las que destinaba para cabezas de alguna considerable porción de ellos. Y este cargo no lo confería por lo común, sino a sugetos que en otros empleos de menor consecuencia hubiesen dado todo el lleno a su satisfacción; la cual no se contentaba con poco. Cuatro cualidades principalmente deseaba en los sugetos, en quienes confería estos empleos de primera estimación; amor a la justicia, con vigorosa resolución para hacerla observar en todo; desinterés, zelo de su servicio, y una experimentada prudencia; de las cuales había de ser como fundamento una más que vulgarmente conocida cristiandad. El examen de estas prendas no lo fiaba a otro que a sí mismo, ni se daba por satisfecho de encontrarlas en ésta o en la otra experiencia, multiplicando todas las pruebas que pudieran dexar sin recelo la conciencia más escrupulosa. Y hallando en un sugeto perfectamente acreditado el desvelo de sus observaciones, no dudaba confiarle los más apreciables gobiernos.

La presencia del conde de Altamira en Santiago (que por su condición de canónigo honorario de León tomó parte en los oficios capitulares) propició la solución de un enojoso conflicto, que mantenía enfrentado al Cabildo catedralicio con el colegio de los jesuitas. Con ocasión del Año Santo de 1706 un predicador jesuita manifestó que a su parecer no estaba incluida entre los privilegios concedidos por las bulas pontificias la conmutación de los votos privados no reservados. Como la praxis habitual era la contraria, el Cabildo exigió una retractación formal y entre tanto suprimió toda relación con la comunidad jesuita ${ }^{35}$. La situación se prolongó por quince años, sin que se llegara a un acuerdo razonable. Sin duda los jesuitas obtuvieron la mediación del Conde, y en las Actas Capitulares ${ }^{36}$ ha quedado recogida la correspondencia entre el arzobispo, el cabildo, el conde y el rector del colegio. No es aventurado suponer que el alcalde mayor, movido a su vez por su hijo, hubiera interpuesto sus buenos oficios ${ }^{37}$.

\footnotetext{
${ }^{35}$ E. Rivera Vázquez, Los jesuitas en Galicia, p. 555-560.

${ }^{36}$ Actas Capitulares 480 (1721) f. 3s. 284-292. 
La correspondencia del estudiante teólogo durante el segundo semestre de 1727 (única que se conserva de ese año) y que ahora por primera vez conocemos ${ }^{38}$, nos introduce en el ambiente universitario salmantino, excitado en aquellos meses de julio-agosto con los festejos que "la juventud triunfante" de los jesuitas y los colegiales de San Salvador de Oviedo dedicaron a los recientemente canonizados Luis Gonzaga con Estanislao de Kostka y Toribio de Mogrovejo; o con los recelos teológicos que suscitan en la comunidad jesuita las noticias de Roma sobre la aprobación que el papa dominico, Benedicto XIII, habría dado a las tesis tomistas, combatidas por el estudiante leonés en un acto mayor académico. Es el año también de su ordenación sacerdotal, recibida en 28 de octubre, con los preparativos y emociones concomitantes en un religioso ferviente. Pero fue también el año de un doloroso enfrentamiento con su padre, que llegó a la ruptura de toda comunicación. Al no conocer más que las respuestas del hijo, ignoramos los motivos que la suscitaron y su posible manifestación en los meses anteriores.

El primer signo aparece en una carta del 20 de agosto.

Padre y Señor mio. Si vm quisiera tener presente que de orden suya di 60 reales por el P. Sempil ${ }^{39}, 15$ para la fiesta de nuestra canonización, 120 para los breviarios, 18 para un hebdomadario, 24 que costaron dos pañuelos, 32, dos libras de tabaco; 15 y medio, 2 (dos palabras tachadas: al margen guillotinado) / que estu ? més fu ? sa, ms/, quizá se escandalizaría vm menos, y no se quexara tanto. Si vm no cree esta cuenta, no tengo yo la culpa; si retraxere los socorros, me conformaré con la voluntad de Dios, y si avisare a mis Superiores, son prodentes y se harán cargo de la razón Nro. Sr. guarde a vm muchos años como puede. P.S. Olvidabaseme decir que 25 años de edad, la sotana de la Compañía y los sagrados órdenes que estoi para recibir, (podían: tachado) me parece podían fundar algún derecho, para que Alexandro ${ }^{40}$ no fuese árbitro de las reprensiones que vm me da, y que yo agradezco.

${ }^{37}$ La documentación de la casa de Altamira sobre este asunto se conserva en la "Bibliothèque Publique et Municipale" de Ginebra. De allí se me comunica amablemente que en el legado no aparece ningún documento de los Isla.

${ }^{38}$ Biblioteca de Palacio, II-1768.

${ }^{39}$ Fco. Xavier Sempill, escocés, connovicio y condiscípulo de Isla, estudiaba en Lovaina, desde donde le enviaba las últimas novedades de la controversia jansenista.

${ }^{40}$ Alejandro Gómez de Castro, ayudante de D. José Isla en la administración, testigo en los testamentos de ambos cónyuges, será a mediados de siglo alguacil mayor y por fin contador mayor.

"CUADERNOS DE ESTUDIOS GALLEGOS", Tomo XLI, Fascículo 106, Santiago 1993-94. 
Y con la misma fecha copia pocas páginas después:

Ra. a mi Padre. Teniendo, como tengo, por menor inconveniente el padecer yo necesidad, que el causar a vm solicitud, a mí desasosiego y murmuraciones a los confidentes, con d?pen? da conforme a la santa libertad del religioso estado que profeso; desde ahora para siempre renuncio a todos los socorros que podía esperar de la cristiana caridad de vm, y protesto que no pediré ni admitiré asistencia o socorro alguno por su parte, que no sea esponténeo, gratuito, liberal y sin el gravamen de dar cuenta de su bueno y mal uso a otros que no sean los Superiores de la Compañía. En Salamanca, a 20 de agosto.

Y el mismo día o el siguiente:

Padre y Señor mio. Va la cuẹta que se me pide, y en lo demás haga $\mathrm{vm}$. lo mejor que le pareciere. Sólo siento que Alexandro sea árbitro de las reprehensiones que vm me da, y que yo agradezco. Estoi para ordenarme de Misa en el mes de septiembre o en el de octubre. Vea vm a quien de los de casa quiere que escoja por padrino.

Se adivina que el rígido administrador de los bienes de Altamira no aplicaba otros métodos para sus asuntos familiares. Y quizá no sea aventurado suponer que se mantenía viva en el subconsciente la frustración producida por la no esperada vocación del hijo. Este por su parte se esforzaba por evitar cualquier ocasión de conflicto. Con fecha de 22 de octubre escribe dos cartas: una al P. Croce ${ }^{41}$, su amigo más íntimo, que desde Salamanca acababa de ser destinado a maestro de filosofía en Santiago, en donde tendría que hacer los buenos oficios de mediador; y otra a su padre, plena de sumisión y respeto.

Mi P. Croce. Agradezco a VR la caridad con que se interesa en sosegar el sentimiento de mi padre, cuyo genio dominante habrá de ocasionarle muchas pesadumbres. Ni hallo otro remedio que el de romper enteramente nuestra conrrespondencia de cartas, contentandonos con tenerla de oraciones y buenos deseos; porque hablando ingenuamente, mi genio es muy semejante al de su merced, y por eso tan opuesto. No obstante, si VR insiste en que le escriba, dispongame allá la carta y enviela, que yo la

${ }^{41}$ El vitoriano Adrián Antonio Croce y Tourlon, unos años mayor que Isla, había sido su profesor de humanidades en Villagarcía en 1719-21. Isla sólo pone encima de él a sus padres.

"CUADERNOS DE ESTUDIOS GALLEGOS", Tomo XLI, Fascículo 106, Santiago 1993-94. 
trasladaré; porque si la dicto yo, no he de acertar a mudar de estilo, y se me ha de ir la pluma hacia lo que siento en el corazón.

Padre y Señor mio. Vm puede corregirme, amonestarme y reprehenderme como quisiere, quando gustare y en la conformidad que mejor le pareciere, sin hacer caso de expresiones mías más secas que significativas, como primeros ímpetus de un genio sensible y poco mortificado; estando cierto de que en la voluntad siempre conservo y conservaré el filial amoroso respeto que debo profesar a aquel de quien recibí el ser. No juzgue vm que me arranca esta satisfación el sentimiento de verme privado de sus socorros, más que el dolor de haber mortificado a vm; porque desde luego protesto que si a los principios hubiera recelado que éste podía ser origen de tantas desazones, ni lo pidiera, ni lo admitiría; pues no tengo ánimo tan vil y tan abatido, que,no me sea más tolerable qualquiera necesidad que el menor disgusto de vm. Y así quedo, no sólo conforme, sino muy gozoso, por verme libre de el principal motivo que ocasionaba a vm tan crecidas pesadumbres. Quizá con el nuevo estado de sacerdocio, que recibiré el día de S. Simón y Judas, habiendo ya recibido el domingo pasado el orden de epístola, me concederá N.S. la luz que tanto necesito y que de veras le pido, como que guarde a vm.

A continuación se copia otra carta al P. Croce de la que parece deducirse que el indomable asturiano no cedía fácilmente en su enojo, y que había devuelto a su hijo alguna carta. Los subrayados son de Isla.

Mi P. Croce. Confieso que aun con toda mi advertencia, de que me precio tanto, y aun después de la nota de VR, no he podido conocer en qué consiste el desahogo (o el otro nombre, que le corresponde) de la carta que se me devuelve. Lo que mi advertencia ha conocido muchos ha, es que mi padre, por su humor dominante, es tan fácil de resentirse, como de dar que sentir a otros; y también ha conocido mi grande advertencia, que el genio de su merced y el mio son muy opuestos porque son muy semejantes. Me lleno de empacho cuando veo, que su merced ha descubierto con facilidad lo que yo juzgaba digno de que estuviese eternamente sepultado. No obstante, porque más me precio de dócil que de advertido, y por complacer a VR, escribo esa carta, que jamás escribiría motu proprio, ni por otro que me hiciese menos fuerza. En lo demás, haga VR lo que le dictare la razón y la conciencia; que yo me consuelo con que cada uno es lo que es delante de Dios, como decía el humilde San Francisco. 
Al día siguiente de su ordenación lo comunica sobriamente a su padre. Padre y Señor mio. Ayer me ordené de misa y mañana digo la primera. Quiera Dios sea para mayor gloria suya. El singular consuelo que experimento en este nuevo estado, se me aguará enteramente si no sé que vm está asegurado de mi reconocimiento; esperando que la mayor inmediación a N.S. me dará la luz que necesito, y vm desea.

Como carecemos de las cartas de 1728 y 1729, ignoramos si se dieron nuevos enfrentamientos entre padre e hijo. Lo probable es que volviera la calma. El irascible asturiano tuvo muy pronto otras preocupaciones. El 17 de marzo de 1728, durante la sede vacante, el Cabildo compostelano, en el ejercicio de sus atribuciones, aceptó la renuncia que uno de los regidores de la ciudad, D. José Bermúdez de Castro y Sangro, hizo en favor de D. José Isla ${ }^{42}$. El renunciante había tomado posesión un mes antes, y había sido apadrinado por el conde de Priegue. No se dan otras explicaciones. Cinco días después, el Conde de Priegue y sus adictos impugnaron este nombramiento, por supuesta incompatibilidad con las funciones de juez de Sta. Eulalia de Cira y alcalde mayor de Altamira, lo que le mantenía en dependencia de la casa condal, y ponía en contingencia sứcondición de residente en la ciudad ${ }^{43}$. Los regidores proponen escribir a la condesa madre pidiendole que releve a Isla de su cargo, "porque luego que entró en dicho empleo, ha empezado a formar cuestiones y diversos pleitos con la ciudad, y hasta ahora no lo ha dexado...". Es cierto que no faltaban precedentes que habían compatibilizado ambas funciones, pero la resolución final fue negativa. Puede suponerse que el aspirante no se daría por vencido, y efectivamente el 10 de abril presentó Real Provisión compulsoria. Siguió el pleito a lo largo del año, y por fin se forzó la votación que fue favorable. En 1734 renunciaría en favor de su pariente de la casa de Altamira.

En 1761, la elección por votación popular del procurador síndico general de la ciudad, que se realizaba a primero de año, reprodujo con inusitada violencia un conflicto que se había manifestado ya en años anterio-

\footnotetext{
${ }^{42}$ Archivo Capitular, Libro 3 de Posesiones (165), f. 286r.

${ }^{43}$ La independencia de los regidores está impuesta en la Nueva Recopilación, Libro VII, tit. III, ley 10, f. 203 v. Un estudio exhaustivo y magistral de la licenciada María López Díaz sobre Oficios municipales en Santiago a mediados del siglo XVIII, en Estudios Mindonienses 6 (1990) 465-665. En el Libro de Consistorios se recogen todas las vicisitudes del conflicto.
} 
res. La corporación municipal pretendía controlar y en el fondo vaciar de sentido el "empleo más honorífico y distinguido del pueblo", encargado de velar por el abastecimiento de los productos de primera necesidad dictando y haciendo cumplir las órdenes pertinentes. Para ello el Concejo proponía dos candidatos escogidos, y ese año salió elegido el marqués de Astáriz. Al pretender darle posesión, una parte del pueblo se amotinó, reclamando como procurador, no a D. José Isla, como afirma por error María López Díaz, sino a su hijo y mayorazgo, José Joaquín de Isla y Losada. Las explicaciones que da el P. Isla a su amigo Ibarrola no dejan lugar a duda sobre la identidad del aspirante, pero nada aclaran sobre el trasfondo del conflicto ${ }^{44}$. ¿Una última batalla del hidalgo asturiano por paladín interpuesto? Lo cierto es que el pueblo asaltó e incendió las Casas Consistoriales, que tuvieron que ser custodiadas durante varias semanas por las tropas. Al fin la Real Audiencia instruyó causa a los culpables e impuso por Real Orden del Consejo de Castilla un sistema de elección indirecta, reservada en exclusiva a los mayordomos de las once parroquias de la ciudad.

Tal como lo presenta el P. Isla, "a excepción de los regidores y sus dependientes, todas las piedras de la ciudad claman contra la injusticia que se hizo (a su hermano) y contra la atroz calumnia que se le levantó". El Concejo había decidido prenderle e hizo venir tropa de La Coruña, para prevenir toda resistencia. Pero José Joaquín se puso a salvo camino de Madrid, "para echarse a los pies del Rey, y solicitar la debida satisfacción a su honor, por tantos caminos atropellado".

Con su habitual sentido de la eficacia, el P. Isla se puso en contacto con sus amigos en la Corte: el procurador de la provincia de Castilla, P. Francisco Nieto, y el bibliotecario real, D. José de Santander. La devoción familiar no le altera el juicio: "si mi hermano tuvo la parte que se le atribuye, sea en buen hora castigado...; pero si no tuvo más culpa, que solicitar que el pueblo le eligiese, y no pesarle de que le hubiese aclamado, que sean castigados los que resultaren reos de la sedición... La verdad yo no la sé, ni en estas ocasiones es fácil saberla, por lo mucho que se miente por las dos parcialidades... Para no errar, pido que se examine exactamente y con sosiego la verdad; que se lean con desconfianza los Autos, forjados de repente, con calor, con pasión, con parcialidad y con poder...". Por lo que

${ }^{44}$ Cartas inéditas del P. Isla, Ed. de L. Fernández SI, Madrid, 1957, p. 233. Otras cartas en p. 30ss y 302 ss.

"CUADERNOS DE ESTUdiOS GALLEGOS", Tomo XLI, Fascículo 106, Santiago 1993-94. 
puede adivinarse en las cartas de aquel año, el negocio se fue alargando en la Corte; José Joaquín logró permanecer en ella sin acudir a las reclamaciones de la sala del crimen de La Coruña; después de la muerte de D. José hay una alusión a "las cartas que se escribieron al Conde pidiendo el empleo de padre" para el hijo. No es posible saber más.

En los varios conjuntos de cartas del P. Isla, hasta ahora conocidos, no se encuentra ningún comentario íntimo sobre los últimos días y muerte de su padre. Ni siquiera con el matrimonio Gortázar-Montiano, al que había hecho las confidencias ya reseñadas; sólo una simple alusión a su fallecimiento el 17 de febrero de 1762 . 